\title{
Simultaneous multipurpose fluorescence imaging with IRDye® 800BK during laparoscopic surgery
}

Citation for published version (APA):

Al-Taher, M., Barberio, M., Felli, E., Agnus, V., Ashoka, A. H., Gioux, S., Klymchenko, A., Bouvy, N., Stassen, L., Marescaux, J., \& Diana, M. (2021). Simultaneous multipurpose fluorescence imaging with IRDye ${ }^{8} 800 \mathrm{BK}$ during laparoscopic surgery. Surgical endoscopy and other interventional techniques, 35(8), 4840-4848. https://doi.org/10.1007/s00464-020-07931-8

Document status and date:

Published: 01/08/2021

DOI:

10.1007/s00464-020-07931-8

Document Version:

Publisher's PDF, also known as Version of record

Document license:

Taverne

Please check the document version of this publication:

- A submitted manuscript is the version of the article upon submission and before peer-review. There can be important differences between the submitted version and the official published version of record.

People interested in the research are advised to contact the author for the final version of the publication, or visit the DOI to the publisher's website.

- The final author version and the galley proof are versions of the publication after peer review.

- The final published version features the final layout of the paper including the volume, issue and page numbers.

Link to publication

\footnotetext{
General rights rights.

- You may freely distribute the URL identifying the publication in the public portal. please follow below link for the End User Agreement:

www.umlib.nl/taverne-license

Take down policy

If you believe that this document breaches copyright please contact us at:

repository@maastrichtuniversity.nl

providing details and we will investigate your claim.
}

Copyright and moral rights for the publications made accessible in the public portal are retained by the authors and/or other copyright owners and it is a condition of accessing publications that users recognise and abide by the legal requirements associated with these

- Users may download and print one copy of any publication from the public portal for the purpose of private study or research.

- You may not further distribute the material or use it for any profit-making activity or commercial gain

If the publication is distributed under the terms of Article $25 \mathrm{fa}$ of the Dutch Copyright Act, indicated by the "Taverne" license above, 


\title{
Simultaneous multipurpose fluorescence imaging with IRDye ${ }^{\circledR} 800 \mathrm{BK}$ during laparoscopic surgery
}

\author{
Mahdi Al-Taher ${ }^{1,2}$ (1) Manuel Barberio $^{1} \cdot$ Eric Felli $^{1} \cdot$ Vincent Agnus $^{1} \cdot$ Anila Hoskere Ashoka $^{3} \cdot$ Sylvain Gioux $^{1,5}$. \\ Andrey Klymchenko ${ }^{3} \cdot$ Nicole Bouvy $^{2} \cdot$ Laurents Stassen $^{2} \cdot$ Jacques Marescaux $^{4} \cdot$ Michele Diana $^{1,4,5}$
}

Received: 10 June 2020 / Accepted: 24 August 2020 / Published online: 28 August 2020

(c) Springer Science+Business Media, LLC, part of Springer Nature 2020

\begin{abstract}
Background IRDye ${ }^{\circledR} 800 \mathrm{BK}$ is a fluorophore, currently undergoing clinical translation, which has both biliary and renal clearance. To date, there is no description of a fluorophore, which can be simultaneously used for non-invasive, near-infrared fluorescence-based (NIRF) visualization of different structures and perfusion evaluation. The purpose of this study was to evaluate IRDye ${ }^{\circledR} 800 \mathrm{BK}$ for the simultaneous assessment of bowel perfusion, lymphography, ureter and bile duct delineation. Methods Six pigs received a $0.15 \mathrm{mg} / \mathrm{kg}$ dye as a single bolus intravenous injection (IV). With the FLER (fluorescencebased enhanced reality) software, fluorescence intensity (FI) of 5 regions of interest (ROI) in an ischemic bowel loop was measured along with the time to reach the FI peak, and capillary lactate was measured from the same ROI, followed by the assessment of the ureters and bile ducts for a maximal duration of $180 \mathrm{~min}$ after dye administration. In 3 animals, the procedure was initiated via gastroscopic injection of a $0.6 \mathrm{mg}(1 \mathrm{mg} / \mathrm{mL})$ dye in the gastric submucosa followed by lymphography in a NIRF setting.

Results Excellent visualization of the ureters and bowel perfusion was obtained under NIRF imaging. Additionally, the bile duct and gastric lymph ducts and nodes were visualized. A positive correlation was found between the time to peak FI in the ischemic bowel loop and the corresponding capillary lactate levels (rho $0.59, p<0.001$ ).

Conclusion In this study, we successfully demonstrated the simultaneous multipurpose IRDye ${ }^{\circledR}$ 800BK applicability during laparoscopic surgery. This fluorophore has the potential to become a powerful and versatile image-guided surgery tool.
\end{abstract}

Keywords Ureteral visualization $\cdot$ Bowel perfusion $\cdot$ Lymphography $\cdot$ Bile duct imaging $\cdot$ Laparoscopic surgery $\cdot$ Nearinfrared fluorescence

Electronic supplementary material The online version of this article (https://doi.org/10.1007/s00464-020-07931-8) contains supplementary material, which is available to authorized users.

Mahdi Al-Taher

mahdi.al-taher@ihu-strasbourg.eu

1 Institute of Image-Guided Surgery, IHU Strasbourg, 1, Place de l'Hôpital, 67091 Strasbourg, France

2 Maastricht University Medical Center, Maastricht, The Netherlands

3 Laboratoire de Bio-Imagerie Et Pathologies, UMR 7021 CNRS, Université de Strasbourg, Strasbourg, France

4 Research Institute Against Digestive Cancer, IRCAD, Strasbourg, France

5 ICUBE Laboratory, Photonics Instrumentation for Health, Strasbourg, France
Near-infrared fluorescence (NIRF) imaging is being rapidly adopted as a surgical navigation tool [1]. NIRF provides a real-time enhanced visualization of anatomical structures and/or metabolic information, thanks to the increased tissue penetration of NIR when compared to white light $[2,3]$. NIRF imaging is being studied in multiple surgical applications, including the assessment of bowel perfusion [4-6] to decrease the risk of anastomotic leakage; bile duct [7, $8]$ and ureteral delineation $[9,10]$ to decrease the risk of iatrogenic injury; and lymph node identification $[11,12]$ to aid in oncological resections.

Indocyanine green (ICG) [7, 13-17] is the dye which is most extensively studied and used in clinical research and practice, as it has been approved by the FDA (Food and Drug Administration) for clinical use and it is well-known due to its established clinical applications in the assessment of hepatic blood flow, assessment of the choroidal blood flow, 
and measurement of cardiac output [18]. This facilitated its introduction to new applications in NIRF imaging. Since ICG is exclusively cleared by the liver, it cannot be used for non-invasive ureteral delineation and it requires direct intra-ureteral injection or retrograde catheter insertion for this purpose [19]. The clinically available methylene blue (MB) is a dye, which is partially cleared by the kidney and it was studied for this purpose. However, although the feasibility of intraoperative ureteral delineation under NIRF imaging with MB has been proven [9, 20], it failed to visualize all the ureters studied in clinical studies, which may originate from the optical properties of MB that are suboptimal for high tissue penetration, since MB has a lower brightness and emits a fluorescence signal near the lower edge of the NIRF range [19].

Consequently, several new fluorophores have been designed for ureteral imaging $[10,19,21]$ including the IRDye ${ }^{\circledR} 800 B K$ dye (nerindocianine sodium) (LI-COR Inc., USA). The IRDye ${ }^{\circledR} 800 \mathrm{BK}$ dye has a molecular weight of $1113 \mathrm{~g} / \mathrm{mol}$, an average mass of $1025.213 \mathrm{Da}$ and consists of the chemical components C44H52N2O16S5 which enable a partial renal and hepatic clearance. It has a maximum absorption at $774 \mathrm{~nm}$ and a maximum emission at $790 \mathrm{~nm}$. Due to its hydrophilicity, it is primarily cleared by the kidneys, which allows non-invasive intraoperative ureteral imaging [22]. Due to its partial hepatic clearance, this dye was also successfully studied for bile duct visualization in an earlier pre-clinical study [23]. However, the possibility that the IRDye ${ }^{\circledR} 800 \mathrm{BK}$ dye could be useful in other applications including perfusion evaluation and fluorescence-based lymphography has not been evaluated yet.

During laparoscopic surgery, it is essential for the surgeon to simultaneously clearly recognize various structures to improve the safety and efficiency of the procedure. However, to date, the majority of the studies on NIRF have been focusing on the visualization of a single structure or organ during laparoscopy.

In our current study, we evaluated the potential of the IRDye ${ }^{8} 800 \mathrm{BK}$ dye for the simultaneous, intraoperative, multipurpose visualization of organs and tissues in combination with a commercially available NIRF imaging system.

\section{Materials and methods}

\section{Animals}

Six mature, female pigs (Sus scrofa domesticus, ssp. Large White; mean weight $44.7 \pm 7.97 \mathrm{~kg}$ ) were included and were managed according to French laws for animal use and care and according to the directives of the European Community Council (2010/63/EU) and ARRIVE guidelines [24]. The present study is part of the Endoscopic Luminescent
Imaging for Oncology Surgery (ELIOS) project and was approved by the local ethical committee on animal experimentation (ICOMETH No. 38.2016.01.085), and by the French Ministry of Superior Education and Research (MESR) (APAFIS\#8721-2017013010316298-v2). The pigs were housed in individual stable boxes and had access to food and water.

Animals received an intramuscular (IM) injection of Zolazepam + Tiletamine $10 \mathrm{mg} / \mathrm{kg}$ (Zoletil ND, Virbac, France) as premedication. Anesthesia was induced by means of IV injection of Propofol $3 \mathrm{mg} / \mathrm{kg}$ (Propofol Lipuro ND, B Braun, France) + Rocuronium $0.8 \mathrm{mg} / \mathrm{kg}$ (Esmeron ND, MSD, France) allowing intubation and mechanical ventilation. Pigs were sedated during the experiment via inhalation of isoflurane 2-3\% (Isoflurin ND, Axience France) + Oxygen. Buprenorphine (Buprecare ND, Axience, France) $0.01 \mathrm{mg} / \mathrm{kg}$ IM was used as a painkiller. At the end of the experiments, pigs were sacrificed under deep anesthesia (Isofluran 5\%) with a lethal IV injection of Pentobarbital $40 \mathrm{mg} / \mathrm{kg}$ (Exagon ND, Axience, France).

\section{Dye preparation}

The IRDye ${ }^{\circledR} 800 \mathrm{BK}$ dye was prepared and used following the manufacturer's instructions. The powder was diluted in a sterile phosphate-buffered saline (PBS) solution to a concentration of $1 \mathrm{mg} / \mathrm{mL}$. Based on earlier experiences [21, 23], which have shown a successful ureteral and bile duct delineation in a pig model, we chose an IV concentration of $0.15 \mathrm{mg} / \mathrm{kg}$ body weight. For the gastric submucosal dye injection, we chose $0.6 \mathrm{mg}(1 \mathrm{mg} / \mathrm{mL}, 0.6 \mathrm{~mL})$ as the empirical total amount of dye representing a preliminary dose.

\section{Surgical procedure}

A pneumoperitoneum was created with a Veress needle and a $12 \mathrm{mmHg}$ pressure of carbon dioxide gas. A $10 \mathrm{~mm}$ supraumbilical trocar was introduced into the abdominal cavity. The rest of the procedure was performed under laparoscopic vision with a commercially available NIR laparoscope (D-Light-P, KARL STORZ, Germany). Four additional $10 \mathrm{~mm}$ and $5 \mathrm{~mm}$ working trocars were inserted. A jejunal loop with a length of approximately $10 \mathrm{~cm}$ was identified and loosely suspended using 3 transparietal sutures with polypropylene (Prolene, Ethicon ${ }^{\mathrm{TM}}$, Johnson \& Johnson Health Care Systems Inc., USA) 3/0 threads, followed by the ligation of 3 to 4 peripheral mesenteric arteries and veins of this loop with a bipolar vessel-sealing device (LigaSure $^{\mathrm{TM}}$ Maryland, Covidien, USA), as can be seen in Fig. 1. This model is a simulation of an ischemic loop as described in an earlier study [25]. In this ischemic intestinal loop, 5 regions of interest (ROIs) were identified and marked with a surgical pen. The locations of these regions of interest 
were as follows: (1) left lateral border, (2) $2.5 \mathrm{~cm}$ from the left lateral border, (3) middle of the loop, (4) $2.5 \mathrm{~cm}$ from the right lateral border, and (5) right lateral border (Fig. 1). After $30 \mathrm{~min}$ of ischemia, the laparoscope was shifted to a NIRF mode and $0.15 \mathrm{mg} / \mathrm{kg}$ of IRDye ${ }^{\circledR} 800 \mathrm{BK}$ was injected intravenously. Ventilation was suppressed for $60 \mathrm{~s}$ to stop the breathing motion during video capture. Directly after NIRF imaging, local capillary lactates were measured on blood samples obtained by puncturing the serosa at each of the 5 ROIs. Blood was aspirated with a $2 \mathrm{~mL}$ serological pipet (Falcon, Beckton Dickinson Labware, USA) attached to an electric aspirator (PipetBoy ${ }^{\mathrm{TM}}$, Integra biosciences, USA) and instantly measured using a handheld portable lactate analyzer (EDGE®, ApexBio, Taipei, Taiwan). Lactate is the end product of the glycolysis and its accumulation reflects a lowered mitochondrial activity in the presence of reduced $\mathrm{O} 2$ tension. This method has been described earlier in a study on "metabolism-guided bowel resection" [26].

Since the fluorescent intensity depends on the distance between light source and target, a standard reference calibration aid, yielding a constant signal when illuminated by the near-infrared light [25], was used. This so-called reference card (Green balance ICG reference card, Diagnostic Green $\mathrm{GmbH}$, Germany) was introduced through a $10 \mathrm{~mm}$ trocar and was constantly held in the laparoscopic view to help for the future analysis of the video recordings of the procedure.

After the NIRF analysis of bowel perfusion and blood sampling for lactate analysis, alternating NIRF imaging of the left ureter and bile duct was performed at fixed time points for a total duration of 120 to $180 \mathrm{~min}$. For these structures, no dissection was performed, and the peritoneum was kept intact.

Additionally, in the last 3 included pigs, the procedure was initiated with the gastroscopic injection of a $0.6 \mathrm{mg}$ $(1 \mathrm{mg} / \mathrm{mL})$ dye in the gastric submucosa under laparoscopic guidance, followed by a laparoscopic assessment of lymph nodes and lymph ducts in a NIRF setting for a total duration of $10 \mathrm{~min}$.

\section{Perfusion analysis software}

The amplitude of fluorescence intensity variation is proportional to the amount of fluorescent dye diffused in the tissue and is consequently a marker of tissue perfusion [27]. The majority of studies on NIRF evaluation of bowel perfusion were performed in a static manner, taking only the relative FI into account without considering the diffusion of the fluorescent dye over time. To overcome these issues, we evaluated the IRDye ${ }^{\circledR} 800 \mathrm{BK}$ dye with the dedicated image analyzer software (ER-PERFUSION, IRCAD, France) to obtain fluorescence-enhanced reality (FLER). This method has been described in detail by our group in a previous study [4]. The software computes the time to peak (TTP) for each pixel, the time for the fluorescence signal to reach its maximum. To prevent the risk of bias, the software does not use the minimum and the maximum of the fluorescence signal but the first and last quartile. Using the first and last quartile ensures that fluorescence signals are analyzed during a period during which the increase in the fluorescence signal is constant.

\section{Statistical analysis}

Statistics were performed using GraphPad 8.3 (GraphPad Software ${ }^{\circledR}$, USA). A Spearman's rho was calculated to correlate local lactates with TTP parameters measured with the FLER software. A $p<0.05$ was considered statistically significant. Normalized fluorescence (NF) is calculated by the FI of the target divided by the FI of the reference card in the same screenshot to minimize the bias of the differences in distance between the light source and the target organ. By using the reference card as a calibration tool, it was possible to compare interoperative and intraoperative findings in all pigs.

\section{Cell culture and microscopy details}

To evaluate the cellular uptake of IRDye ${ }^{\circledR} 800 \mathrm{BK}$ and hence to determine the potential complete clearance of the dye from the body, fluorescence microscopy analysis was performed on a cell culture. HeLa cells (Human cervical cancer cell lines) (ATCC $®$ CCL-2) were grown in Dulbecco's modified Eagle medium (DMEM, Gibco-Invitrogen, USA), supplemented with a $10 \%$ fetal bovine serum (FBS, Lonza, Switzerland) and a $1 \%$ antibiotic solution (penicillin-streptomycin, Gibco-Invitrogen) at $37^{\circ} \mathrm{C}$ in a humidified atmosphere containing $5 \% \mathrm{CO}_{2}$. Cells were seeded onto a chambered coverglass (IBiDi®, Germany) at a density of $1 \times 10^{5}$ cells/well $24 \mathrm{~h}$ before microscopy measurement. For imaging, the medium was removed, and the remaining attached cells were washed with 1X PBS and added with a reduced serum medium (Opti-MEM, Gibco-Invitrogen) containing the IRDye ${ }^{\circledR} 800 \mathrm{BK}$ dye $(1 \mu \mathrm{M})$ and incubated for $2 \mathrm{~h}$ at $37^{\circ} \mathrm{C}$. Fluorescence images were captured before and after washing the cells with $1 \mathrm{X}$ PBS. Fluorescence imaging was performed in an epifluorescence mode using the Nikon Ti-E inverted microscope with a $60 \times$ objective. The sample was excited with a $730 \mathrm{~nm}$ LED source and the emission was collected in the NIR channel with an $810 / 90$ band-pass filter. The ImageJ software was used to process fluorescence images.

\section{Results}

In Table 1, the weight, total amount of dye, lactate values of the regions of interest in the ischemic bowel loop, and the length of the surgical observation are summarized 
as well as the organs which were successfully visualized with NIRF imaging. The intraoperative visual results of this study are shown in the supplementary video (Supplemental Digital Content 1).

\section{Bowel perfusion model}

In all included pigs, a clear macroscopic NIRF visualization of the perfusion was performed (Fig. 1), in which regions 1 and 5 had a faster development of brightness as compared to regions 2,3 , and 4 . This is also objectively proven with the FLER analysis of the TTP in which ROI 3 had the highest TTP with a significant difference with ROI 1 and ROI 5 (Fig. 2a). ROI 3 also had a significant higher level of lactate than ROI 1, 4, and 5 (Fig. 2b). A significant positive correlation was found between the time to peak FI in the ischemic bowel loop and the corresponding capillary lactate levels (Spearman's rho 0.59, $p<0.001$ ) (Fig. 2c).

\section{Ureteral imaging}

The first ureteral evaluation under NIRF imaging was performed between 10 and $20 \mathrm{~min}$ after dye administration. At this first evaluation, the ureter could be clearly distinguished from its surroundings under NIRF imaging (Figs. 3, 4a). All ureters remained clearly visible until the end of the procedure (max. $180 \mathrm{~min}$ ) with no significant change in the fluorescence signal over time between the time points and between the analyzed porcine ureters (Kolmogorov-Smirnov $p>0.11$ for each measured time point). Maximum fluorescence intensities were seen during the peristaltic contractions of the ureter (Fig. 3). In one pig, the left ureter was transected on purpose at the end of the procedure. Under NIRF imaging, this ureteral damage and the leakage of urine could be clearly visualized as shown in the supplementary video.

\section{Bile duct imaging}

The first bile duct evaluation under NIRF imaging was performed between 10 and 20 min after dye administrations.

Table 1 Summary of experimental results

\begin{tabular}{|c|c|c|c|c|c|c|}
\hline & Pig 1 & Pig 2 & Pig 3 & $\operatorname{Pig} 4^{\mathrm{b}}$ & Pig 5 & Pig 6 \\
\hline Weight (kg) & 44 & 33 & 58 & 45 & 43 & 45 \\
\hline Dye in $\mathrm{mg}$ & 6.6 & 4.95 & 8.7 & 6.75 & 6.45 & 6.75 \\
\hline Systemic lactate ${ }^{a}$ & 0.7 & 1.5 & 0.8 & 4.4 & 0.7 & 1.3 \\
\hline Lactate region of interest 1 & 2.2 & 1.6 & 1.5 & 2.2 & 2 & 1.7 \\
\hline Lactate region of interest 2 & 0.7 & 3.3 & 4.1 & 5.4 & 0.8 & 1.4 \\
\hline Lactate region of interest 3 & 6.2 & 3.5 & 4.5 & 4.5 & 1.8 & 3.8 \\
\hline Lactate region of interest 4 & 1 & 1.5 & 0.7 & 2.5 & 0.7 & 0.7 \\
\hline Lactate region of interest 5 & 0.7 & 1.6 & 0.7 & 3.4 & 0.7 & 1.1 \\
\hline Structures visualized & $\begin{array}{l}\text { Perfusion } \\
\text { Bile duct } \\
\text { Ureter }\end{array}$ & $\begin{array}{l}\text { Perfusion } \\
\text { Bile duct } \\
\text { Ureter }\end{array}$ & $\begin{array}{l}\text { Perfusion } \\
\text { Bile duct } \\
\text { Ureter }\end{array}$ & $\begin{array}{l}\text { Perfusion } \\
\text { Bile duct } \\
\text { Ureter } \\
\text { Lymph nodes }\end{array}$ & $\begin{array}{l}\text { Perfusion } \\
\text { Bile duct } \\
\text { Ureter } \\
\text { Lymph nodes }\end{array}$ & $\begin{array}{l}\text { Perfusion } \\
\text { Bile duct } \\
\text { Ureter } \\
\text { Lymph nodes }\end{array}$ \\
\hline Length of observation (minutes) & 120 & 180 & 180 & 180 & 180 & 120 \\
\hline
\end{tabular}

${ }^{a}$ Lactate values are in $\mathrm{mmol} / \mathrm{L}$

${ }^{\mathrm{b}}$ In this pig, a bronchospasm occurred before intubation leading to low saturation levels and tachycardia for several minutes. This may have influenced lactate values

Fig. 1 Near-infrared fluorescence visualization of the ischemic bowel loop. An ischemic bowel loop set up in white light, near-infrared fluorescence (NIRF), and fluorescence-enhanced reality (FLER) mode, respectively. 1-5: marked regions of interest (ROIs)

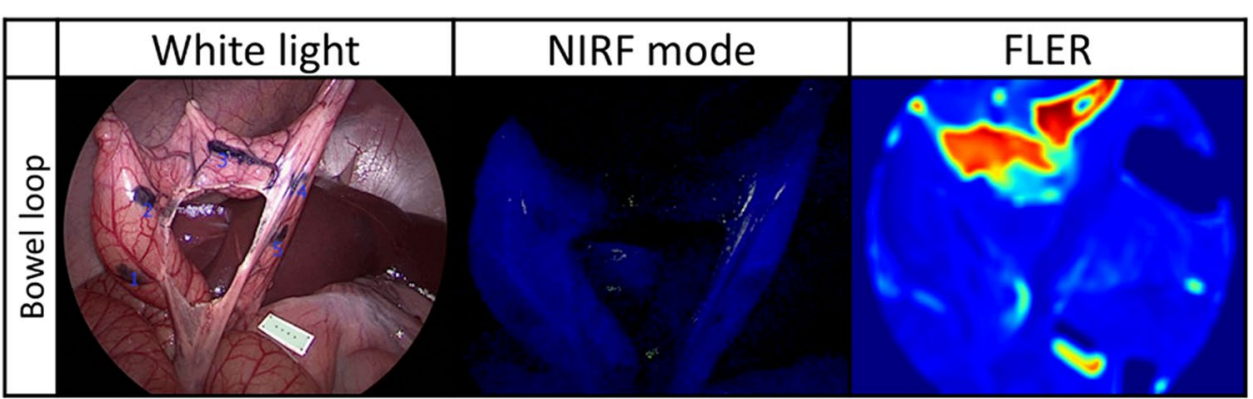



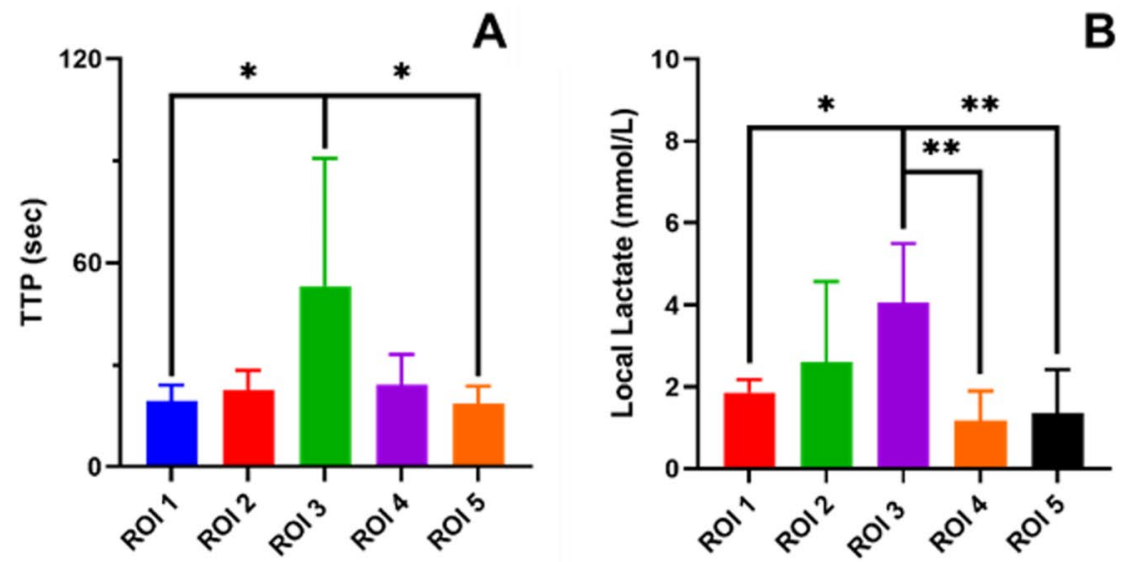

B

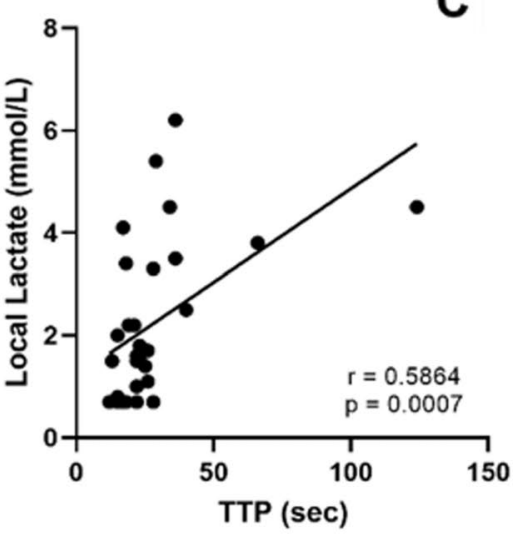

Fig. 2 Results of bowel perfusion analysis. A Time to peak fluorescence in seconds (TTP) for each region of interest (ROI) studied, showing a significant difference between ROI 3 and ROI 1 and ROI 5. B The local lactate level was significantly different between ROI
3 and ROI 1, 4, and 5. C A significant positive correlation was found between the time to peak FI in the ischemic bowel loop and corresponding capillary lactate levels (Spearman's rho 0.59, $p<0.001$ )

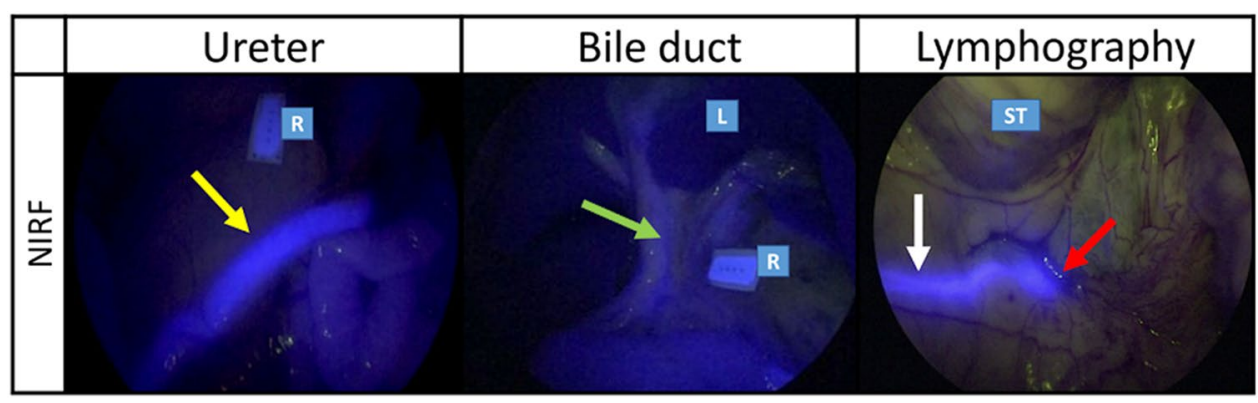

Fig. 3 Multipurpose fluorescence visualization in various applications. Left ureter after $20 \mathrm{~min}$ (yellow arrow), bile duct after $30 \mathrm{~min}$ (green arrow), gastric lymph duct (white arrow) and lymph node (red arrow) after 5 min of dye injection, respectively, seen under NIRF imaging. $L$ Liver, $R$ ICG reference card, $S T$ stomach (Color figure online)

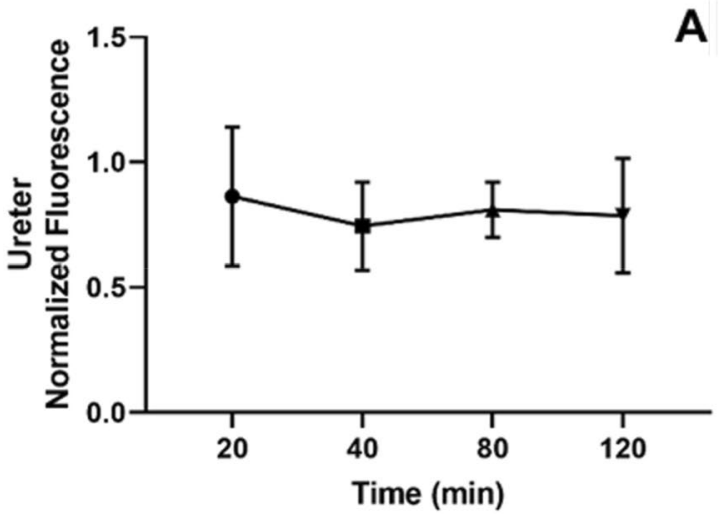

Fig. 4 Results of ureteral and bile duct NIRF imaging. A Normalized fluorescence of the ureter at different time points after dye administration. B Normalized fluorescence of the ureter at different time points

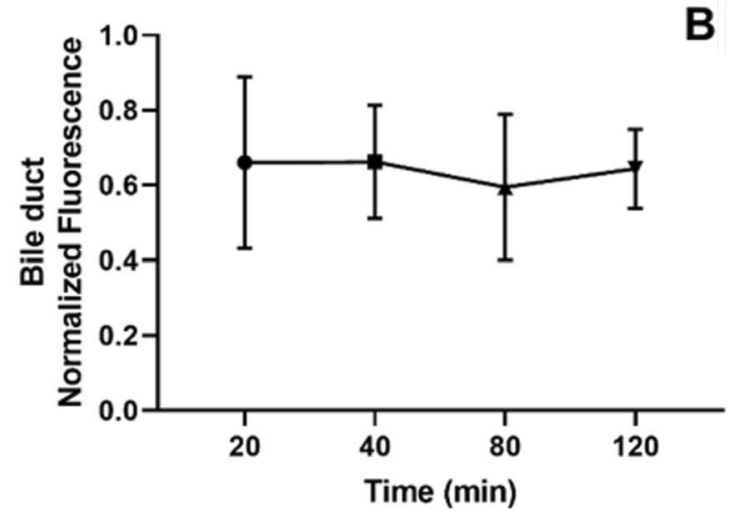

after dye administration. Normalized fluorescence is the product of the fluorescence intensity of the target divided by the fluorescence intensity of the reference card 
At this first evaluation, the bile duct could be distinguished from its surroundings under NIRF imaging (Figs. 3, 4b). Subjectively, based on visual findings, the bile duct became less distinguishable from its surroundings over time. This finding is supported by a statistically reduced NF of the bile duct after 40 min of dye administration onwards. A Mann-Whitney test to assess whether the NF of the bile duct is greater than the NF of the background, showed a statistically significant difference for time points up to $40 \mathrm{~min}$ $(p<0.0473)$.

\section{Gastric lymph node imaging}

In the 3 randomly selected pigs in which a gastroscopyassisted submucosal dye injection was performed, a clear delineation of one or more lymph ducts appeared, and within $5 \mathrm{~min}$, the corresponding lymph node could be clearly identified under NIRF imaging as seen in Fig. 3.

\section{Cell culture}

HeLa cells were incubated with the IRDye ${ }^{\circledR} 800 \mathrm{BK}$ dye $(1 \mu \mathrm{M})$ in optiMEM, for $2 \mathrm{~h}$ at $37{ }^{\circ} \mathrm{C}$ after which fluorescence images were obtained. Fluorescence images showed no cellular uptake and only background fluorescence was observed. Analysis of fluorescence images confirmed that there was no cellular uptake of the dye (Fig. 5). The negatively charged sulfonate groups, present on IRDye ${ }^{\circledR} 800 \mathrm{BK}$, prevent the dye molecule from crossing the cell plasma membrane, which results in poor cellular uptake.

\section{Complications}

No intraoperative dye-related complications occurred. However, pig No. 4 developed a bronchospasm after induction but before intubation, which resulted in reduced levels of blood oxygen saturation for several minutes after which a successful intubation was achieved. This may have influenced the higher levels of systemic lactate found in this pig.

\section{Discussion}

In this pre-clinical study, we have successfully demonstrated the simultaneous, multipurpose NIRF imaging of several intra-abdominal organs using the IRDye ${ }^{\circ} 800 \mathrm{BK}$ dye and a commercially available fluorescence imaging system during laparoscopic surgery.

One of the advantages, as compared to ICG, is that this dye has both renal and hepatic clearance, which allows its use for ureteral and biliary imaging as demonstrated in this study and in earlier studies. The majority of ureteral injuries are identified postoperatively [28]. In this study, the ureters were clearly identified under NIRF imaging in all animals. Additionally, by deliberately transecting the ureter, it was possible to easily recognize and locate the ureteral injury under NIRF imaging intraoperatively. This finding potentially allows the surgeon to prevent any ureteral injury, and if an injury occurs, to repair the injury during the same procedure and overcome the sequelae [29] of missed ureteral lesions. In a study by Barnes et al., it was demonstrated that the IRDye ${ }^{\circledR} 800 \mathrm{BK}$ dye was also a promising alternative to ICG in visualizing the urethra using NIRF imaging. It was shown that this dye has a greater depth of penetration and may allow for an earlier detection of the urethra intraoperatively, thereby preventing wrong plane surgery during low rectal resections [30].

Importantly, as the clinically most relevant finding of this study, we have demonstrated that this dye allows to clearly visualize intestinal perfusion in combination with ureteral
Fig. 5 Fluorescence microscopy images of HeLa cells stained with IRDye ${ }^{8} 800 \mathrm{BK}$. HeLa cells were incubated with IRDye ${ }^{\circledR} 800 B K(1 \mu \mathrm{M})$ in optiMEM, incubated for $2 \mathrm{~h}$ at $37^{\circ} \mathrm{C}$. The rows represent the images before and after washing respectively. Samples were excited with a $730 \mathrm{~nm}$ LED source and the emission was collected in NIR channel with an $810 / 90$ band-pass filter. No cellular uptake was observed even after $2 \mathrm{~h}$ of incubation with the dye. Scale bar $10 \mu \mathrm{m}$

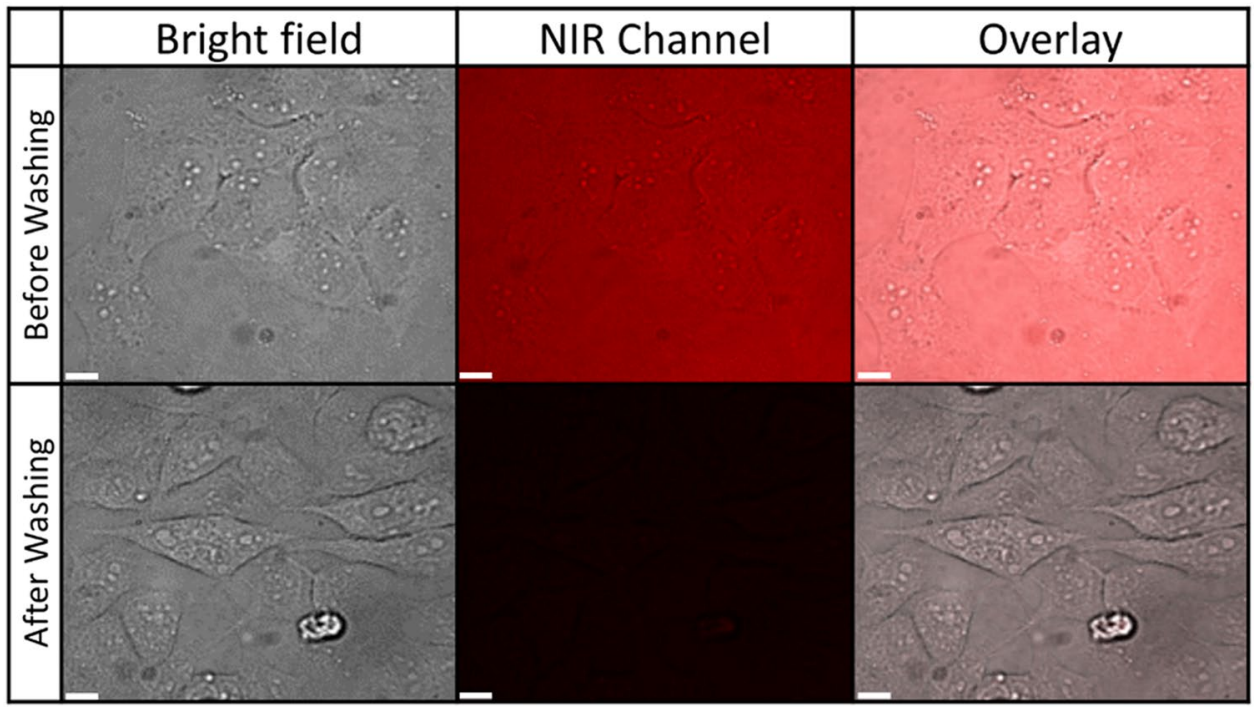


delineation. This finding is particularly valuable for colorectal surgeons as it is pivotal for the surgeon to identify the course of the ureter to prevent any iatrogenic ureteral injuries and to assess bowel vascularization prior to anastomosis creation to minimize the risk of anastomotic leakage. With the approach presented, there is no need to insert a ureteral stent to locate the ureter, nor is there a need for 2 different fluorescence dyes to visualize bowel perfusion and the ureter simultaneously. Additionally, a significant positive correlation was found between the time to peak FI in the ischemic bowel loop and corresponding capillary lactate levels (rho 0.59, $p<0.001$ ). This highlights the importance of an intraoperative quantitative analysis of the NIRF imaging of bowel perfusion using dedicated analysis software such as FLER, which may help to reduce the incidence of anastomotic leaks [26]. We have compared the NIRF findings of this bowel loop to the findings of historical data in which a similar approach was used to create an ischemic bowel loop and visualize the perfusion with a similar NIRF imaging system, after intravenous ICG injection in pigs two hours after the creation of the ischemic bowel loop [4]. An interesting finding is that there was a significantly (Mann-Whitney, $p<0.039$ ) increased absolute value of the TTP for the IRDye ${ }^{\circledR} 800 \mathrm{BK}$ dye in the ischemic zone (ROI 3) as compared to ICG, despite a longer ischemia time (Fig. 6). This suggests that there is a decreased diffusion of the IRDye ${ }^{\circledR} 800 \mathrm{BK}$ dye in less perfused zones, possibly due to the higher molecular weight of this dye $(1113 \mathrm{~g} / \mathrm{mol}$ vs. $775 \mathrm{~g} / \mathrm{mol}$ for ICG), which may improve intraoperative decision-making when assessing the viability of the bowel under NIRF imaging. Since several ICG agents usually contain Sodium Iodide, it is thought that this is the general cause of noted allergic reactions and not the molecular weight per se. IRDye ${ }^{\circledR} 800 \mathrm{BK}$ is not associated with Sodium Iodides and was reconstituted in sterile phosphate-buffered saline for this study. Our group aims to design a comparative study

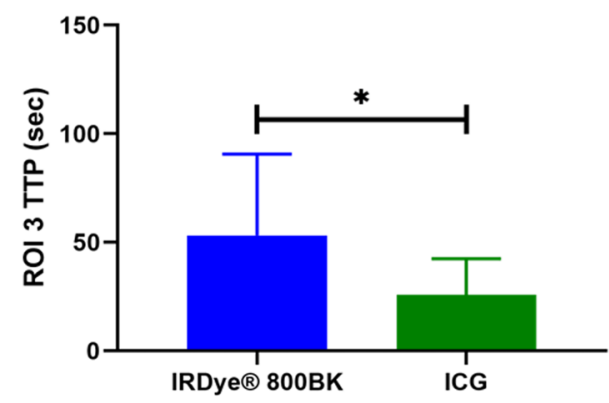

Fig. 6 Comparison of absolute time to peak values at the ischemic region of interest between IRDye ${ }^{\circledR} 800 \mathrm{BK}$ and ICG. Time to peak fluorescence in seconds (TTP) for ROI 3 (ischemic region of interest), showing a significant (Mann-Whitney, $p<0.039$ ) higher TTP for IRDye ${ }^{\circledR} 800 \mathrm{BK}$ compared to ICG between the IRDye ${ }^{\circledR} 800 \mathrm{BK}$ dye and ICG for bowel perfusion in an acute pig model.

In this study, we have also shown the clear visualization of lymph ducts and corresponding lymph nodes in the draining delta within several minutes after local dye injection in the gastric submucosa. This can potentially be used to road-map lymphatic drainage, which can be a determinant for the oncological status of lymph nodes and may aid in decision-making regarding the extent of operative dissection and resection [31] in oncologic surgery.

Finally, we successfully visualized the bile ducts in all animals. However, this was time-dependent as NF decreased over time and the bile duct became less distinguishable from its surroundings from 40 min onwards after dye injection. In this study, it was not possible to study the bile ducts within 10 to 20 min after dye injection. In future studies, it would be of interest to continuously evaluate the behavior of this dye in bile duct imaging directly after administration to find the optimal moment of dye administration in respect to peak fluorescence and to evaluate its potential use for hilar vascular anatomy assessment.

In a study by Ashitate et al. [32], the simultaneous visualization of the bile ducts and the hepatic artery were explored successfully. However, this was performed with a combination of MB, ICG, and ZW800-1 with a dual-channel NIRF system. In this study, the use of two independent wavelengths of invisible NIRF light were explored to provide simultaneous contrast of extrahepatic bile ducts and hepatic arteries. A similar approach was described by Wada et al. [33] where the combination of T700-F with ZW800-1 for NIRF imaging of vessels and kidney, ZW800-3C for lymph nodes, and ESNF31 for adrenal glands, were studied respectively.

The IRDye ${ }^{\circledR} 800 \mathrm{BK}$ dye is currently under evaluation in clinical trials for use in the human setting. Such studies will also provide data on the side effects and adverse reactions to the injection of this dye. One of these studies is a clinical trial performed as a dose escalation study in gynecologic surgery (NCT03106038). The second focuses on the safety and efficacy of this dye in laparoscopic bowel resection and laparoscopic donor nephrectomy (NCT03387410). It is anticipated that FDA approval for clinical use will be achieved (personal communication with the manufacturer).

It is rare in surgery to simultaneously need the visualization of the bile duct, ureter and perigastric lymph nodes at any time as was shown feasible in this study. However, this study was meant to explore the potential width of utility of this dye. In future studies, clinically relevant combinations such as ureteral + bowel perfusion and gastric perfusion + draining lymph nodes could be studied separately.

In this study, which served as a proof-of-concept, we evaluated a fixed dose ( $0.15 \mathrm{mg}$ of dye) per kg body weight. In future research, a dose escalation trial should be performed 
to find the ideal dose for this dye for a combination of organs studied simultaneously.

Due to the operative regimen in which we started with perfusion analysis and moved to ureteral and bile duct imaging afterwards, we cannot draw conclusions on the speed of NIRF visualization of the ureter and bile duct after dye administration. Based on our earlier findings, it is likely that the onset of ureteral and bile duct visualization occurs within a few minutes (around 1 for ureters and around 15 for bile ducts) after dye administration [22, 23].

The novelty of this study lies in the fact that, to the best of our knowledge, there is no prior study presenting the successful identification of the ureter, bile duct, lymph nodes, and quantitative bowel perfusion in a single operative procedure and with a single commercially available NIRF system. This provides surgeons with a potentially powerful tool to enhance the visibility of several organs intraoperatively with a single dye and imaging system. Additionally, the described method was safe, may be easily reproduced, and may subsequently be integrated in the surgical workflow. Based on microscopic analysis, no cellular dye uptake was present, which suggests the complete clearance of the dye from the body over time. In a recently published study, our group successfully demonstrated the feasibility of this dye for ureteral imaging in robotic surgery using the Firefly technology in a pig model. This underscores the potential future application of this dye for both laparoscopic and robotic surgery procedures [34].

Despite the promising results of the current study, the findings must be interpreted with caution. It is known that the porcine peritoneum contains less fat as compared to humans. Consequently, NIRF imaging with this dye during laparoscopy in humans could be negatively influenced by the greater layer of fat. Moreover, although the current preclinical work does suggest a broad application, it is critical that the understanding of the intended use for any potential indication would require a thorough review to include dosing, timing of visualization of any or all targets of interest. This should be the focus of future studies exploring the potential of this novel dye.

\section{Conclusion}

In this pre-clinical study, we successfully demonstrated the simultaneous multipurpose IRDye ${ }^{\circledR}$ 800BK dye applicability during laparoscopic surgery. This dye has the potential to become a powerful and versatile image-guided surgery tool.

Acknowledgements The authors would like to thank Christopher Burel and Guy Temporal for their valuable help in proofreading this manuscript, and special thanks also go to Christopher Burel who did the voice over for the supplemental video.
Funding This work was funded by the ARC Foundation through the ELIOS (Endoscopic Luminescent Imaging for precision Oncologic Surgery) grant. LI-COR Biosciences (Lincoln, USA) provided the fluorescent dye, IRDye ${ }^{\circledR}$ 800BK (nerindocianine sodium), used in this study.

\section{Compliance with ethical standards}

Disclosures Jacques Marescaux is the President of IRCAD, which is partly funded by KARL STORZ, and Medtronic. Michele Diana and Laurents Stassen are members of the Scientific Board of Diagnostic Green. Michele Diana is the recipient of the ELIOS grant. Mahdi AlTaher, Manuel Barberio, Eric Felli, Vincent Agnus, Anila Hoskere Ashoka, Sylvain Gioux, Andrey Klymchenko and Nicole Bouvy have no conflicts of interest or financial ties to disclose.

\section{References}

1. Vahrmeijer AL, Hutteman M, van der Vorst JR, van de Velde CJ, Frangioni JV (2013) Image-guided cancer surgery using nearinfrared fluorescence. Nat Rev Clin Oncol 10:507-518

2. van Manen L, Handgraaf HJM, Diana M, Dijkstra J, Ishizawa T, Vahrmeijer AL, Mieog JSD (2018) A practical guide for the use of indocyanine green and methylene blue in fluorescence-guided abdominal surgery. J Surg Oncol 118:283-300

3. Nguyen QT, Tsien RY (2013) Fluorescence-guided surgery with live molecular navigation - a new cutting edge. Nat Rev Cancer 13:653-662

4. Diana M, Agnus V, Halvax P, Liu YY, Dallemagne B, Schlagowski AI, Geny B, Diemunsch P, Lindner V, Marescaux J (2015) Intraoperative fluorescence-based enhanced reality laparoscopic realtime imaging to assess bowel perfusion at the anastomotic site in an experimental model. Br J Surg 102:e169-176

5. Blanco-Colino R, Espin-Basany E (2018) Intraoperative use of ICG fluorescence imaging to reduce the risk of anastomotic leakage in colorectal surgery: a systematic review and meta-analysis. Tech Coloproctol 22:15-23

6. Jafari MD, Lee KH, Halabi WJ, Mills SD, Carmichael JC, Stamos MJ, Pigazzi A (2013) The use of indocyanine green fluorescence to assess anastomotic perfusion during robotic assisted laparoscopic rectal surgery. Surg Endosc 27:3003-3008

7. Agnus V, Pesce A, Boni L, Van Den Bos J, Morales-Conde S, Paganini AM, Quaresima S, Balla A, La Greca G, Plaudis H, Moretto G, Castagnola M, Santi C, Casali L, Tartamella L, Saadi A, Picchetto A, Arezzo A, Marescaux J, Diana M (2019) Fluorescence-based cholangiography: preliminary results from the IHU-IRCAD-EAES EURO-FIGS registry. Surg Endosc

8. Dip F, LoMenzo E, Sarotto L, Phillips E, Todeschini H, Nahmod M, Alle L, Schneider S, Kaja L, Boni L, Ferraina P, Carus T, Kokudo N, Ishizawa T, Walsh M, Simpfendorfer C, Mayank R, White K, Rosenthal RJ (2019) Randomized trial of near-infrared incisionless fluorescent cholangiography. Ann Surg 270:992-999

9. Al-Taher M, van den Bos J, Schols RM, Bouvy ND, Stassen LP (2016) Fluorescence ureteral visualization in human laparoscopic colorectal surgery using methylene blue. J Laparoendosc Adv Surg Tech A 26:870-875

10. de Valk KS, Handgraaf HJ, Deken MM, Sibinga Mulder BG, Valentijn AR, Terwisscha van Scheltinga AG, Kuil J, van Esdonk MJ, Vuijk J, Bevers RF, Peeters KC, Holman FA, Frangioni JV, Burggraaf J, Vahrmeijer AL (2019) A zwitterionic near-infrared fluorophore for real-time ureter identification during laparoscopic abdominopelvic surgery. Nat Commun 10:3118 
11. Kusano M, Tajima Y, Yamazaki K, Kato M, Watanabe M, Miwa M (2008) Sentinel node mapping guided by indocyanine green fluorescence imaging: a new method for sentinel node navigation surgery in gastrointestinal cancer. Dig Surg 25:103-108

12. Troyan SL, Kianzad V, Gibbs-Strauss SL, Gioux S, Matsui A, Oketokoun R, Ngo L, Khamene A, Azar F, Frangioni JV (2009) The FLARE intraoperative near-infrared fluorescence imaging system: a first-in-human clinical trial in breast cancer sentinel lymph node mapping. Ann Surg Oncol 16:2943-2952

13. Liu YY, Liao CH, Diana M, Wang SY, Kong SH, Yeh CN, Dallemagne B, Marescaux J, Yeh TS (2018) Near-infrared cholecystocholangiography with direct intragallbladder indocyanine green injection: preliminary clinical results. Surg Endosc 32:1506-1514

14. Buda A, Di Martino G, Vecchione F, Bussi B, Dell'Anna T, Palazzi S, Cantu MG, Marchette MD, Milani R (2015) Optimizing strategies for sentinel lymph node mapping in early-stage cervical and endometrial cancer: comparison of real-time fluorescence with indocyanine green and methylene blue. Int J Gynecol Cancer 25:1513-1518

15. Paiella S, De Pastena M, Landoni L, Esposito A, Casetti L, Miotto M, Ramera M, Salvia R, Secchettin E, Bonamini D, Manzini G, D'Onofrio M, Marchegiani G, Bassi C (2017) Is there a role for near-infrared technology in laparoscopic resection of pancreatic neuroendocrine tumors? Results of the COLPAN "colour-andresect the pancreas" study. Surg Endosc 31:4478-4484

16. Baiocchi GL, Diana M, Boni L (2018) Indocyanine green-based fluorescence imaging in visceral and hepatobiliary and pancreatic surgery: State of the art and future directions. World J Gastroenterol 24:2921-2930

17. Ds AV, Lin H, Henderson ER, Samkoe KS, Pogue BW (2016) Review of fluorescence guided surgery systems: identification of key performance capabilities beyond indocyanine green imaging. J Biomed Opt 21:80901

18. Alander JT, Kaartinen I, Laakso A, Patila T, Spillmann T, Tuchin VV, Venermo M, Valisuo P (2012) A review of indocyanine green fluorescent imaging in surgery. Int J Biomed Imaging 2012:940585

19. Slooter MD, Janssen A, Bemelman WA, Tanis PJ, Hompes R (2019) Currently available and experimental dyes for intraoperative near-infrared fluorescence imaging of the ureters: a systematic review. Tech Coloproctol 23:305-313

20. Barnes TG, Hompes R, Birks J, Mortensen NJ, Jones O, Lindsey I, Guy R, George B, Cunningham C, Yeung TM (2018) Methylene blue fluorescence of the ureter during colorectal surgery. Surg Endosc 32:4036-4043

21. van den Bos J, Al-Taher M, Bouvy ND, Stassen LPS (2019) Nearinfrared fluorescence laparoscopy of the ureter with three preclinical dyes in a pig model. Surg Endosc 33:986-991

22. Al-Taher M, van den Bos J, Schols RM, Kubat B, Bouvy ND, Stassen LPS (2018) Evaluation of a novel dye for near-infrared fluorescence delineation of the ureters during laparoscopy. BJS Open 2:254-261
23. van den Bos J, Al-Taher M, Hsien SG, Bouvy ND, Stassen LPS (2017) Near-infrared fluorescence laparoscopy of the cystic duct and cystic artery: first experience with two new preclinical dyes in a pig model. Surg Endosc 31:4309-4314

24. Kilkenny C, Browne W, Cuthill IC, Emerson M, Altman DG, Group NCRRGW (2010) Animal research: reporting in vivo experiments: the ARRIVE guidelines. J Gene Med 12:561-563

25. Diana M, Noll E, Diemunsch P, Dallemagne B, Benahmed MA, Agnus V, Soler L, Barry B, Namer IJ, Demartines N, Charles AL, Geny B, Marescaux J (2014) Enhanced-reality video fluorescence: a real-time assessment of intestinal viability. Ann Surg 259:700-707

26. Diana M, Noll E, Diemunsch P, Moussallieh FM, Namer IJ, Charles AL, Lindner V, Agnus V, Geny B, Marescaux J (2015) Metabolism-guided bowel resection: potential role and accuracy of instant capillary lactates to identify the optimal resection site. Surg Innov 22:453-461

27. Nachiappan S, Askari A, Currie A, Kennedy RH, Faiz O (2014) Intraoperative assessment of colorectal anastomotic integrity: a systematic review. Surg Endosc 28:2513-2530

28. Engel O, Rink M, Fisch M (2015) Management of iatrogenic ureteral injury and techniques for ureteral reconstruction. Curr Opin Urol 25:331-335

29. Abboudi H, Ahmed K, Royle J, Khan MS, Dasgupta P, N'Dow J (2013) Ureteric injury: a challenging condition to diagnose and manage. Nat Rev Urol 10:108-115

30. Barnes TG, Volpi D, Cunningham C, Vojnovic B, Hompes R (2018) Improved urethral fluorescence during low rectal surgery: a new dye and a new method. Tech Coloproctol 22:115-119

31. Cahill RA, Ris F, Mortensen NJ (2011) Near-infrared laparoscopy for real-time intra-operative arterial and lymphatic perfusion imaging. Colorectal Dis 13(Suppl 7):12-17

32. Ashitate Y, Stockdale A, Choi HS, Laurence RG, Frangioni JV (2012) Real-time simultaneous near-infrared fluorescence imaging of bile duct and arterial anatomy. J Surg Res 176:7-13

33. Wada H, Hyun H, Vargas C, Gravier J, Park G, Gioux S, Frangioni JV, Henary M, Choi HS (2015) Pancreas-targeted NIR fluorophores for dual-channel image-guided abdominal surgery. Theranostics 5:1-11

34. Al-Taher M, Okamoto N, Felli E, Agnus V, Barberio M, Gioux S, Bouvy N, Stassen L, Marescaux J, Diana M (2020) Noninvasive near-infrared fluorescence imaging of the ureter during robotic surgery: a demonstration in a porcine model. J Laparoendosc Adv Surg Tech A

Publisher's Note Springer Nature remains neutral with regard to jurisdictional claims in published maps and institutional affiliations. 